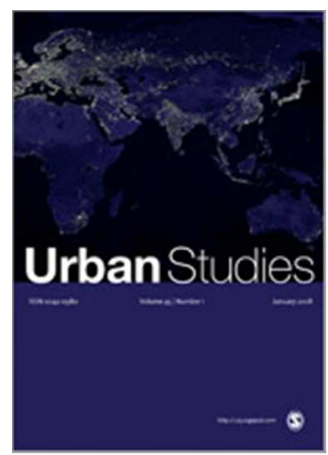

\title{
From resilience to multi-species flourishing: (re)imagining urban-environmental governance in Penang, Malaysia
}

\begin{tabular}{|c|c|}
\hline Journal: & Urban Studies \\
\hline Manuscript ID & CUS-852-17-09.R2 \\
\hline Manuscript Type: & Special Issue \\
\hline $\begin{array}{l}<\mathrm{b}>\text { Discipline: Please select a } \\
\text { keyword from the following list } \\
\text { that best describes the } \\
\text { discipline used in your paper.: }\end{array}$ & Geography \\
\hline $\begin{array}{r}\text { World Region: Please select } \\
\text { the region(s) that best reflect } \\
\text { the focus of your paper. } \\
\text { Names of individual countries, } \\
\text { cities \& economic groupings } \\
\text { should appear in the title } \\
\text { where appropriate.: }\end{array}$ & Southeast Asia, Asia \\
\hline $\begin{array}{l}\text { Major Topic: Please identify up } \\
\text { to } 5 \text { topics that best identify } \\
\text { the subject of your article.: }\end{array}$ & $\begin{array}{l}\text { Agglomeration/Urbanisation, Environment/Sustainability, Governance, } \\
\text { History/heritage/memory, Land Use }\end{array}$ \\
\hline $\begin{array}{l}\text { You may add up to } 2 \text { further } \\
\text { relevant keywords of your } \\
\text { choosing below: }\end{array}$ & urban political ecology, resilience \\
\hline
\end{tabular}




\title{
From resilience to multi-species flourishing: (re)imagining urban-environmental governance in Penang, Malaysia
}

\begin{abstract}
This paper uses the concept of multi-species flourishing to evaluate the potential of emergent urban governance initiatives in Penang, Malaysia, for achieving more socially and environmentally just forms of urban development. In doing so, the paper offers an empirical examination of increasing development pressures on the forested hillsides of Penang, and the significant environmental and socio-cultural implications associated with this activity. This includes the significant flash-flooding and landslides in 2016 and 2017 that have been attributed to unscrupulous hillside developments and deforestation on the island for condominium and highway development. In tracing local responses to these developments, the paper draws attention to the various more-than-human relationships that have been mobilized in preventing further degradation of the environment. I also re-visit the concept of environmental imaginaries to illustrate the close relationship between environmental and social well-being. The paper thus argues that it is important to move beyond concepts of resilience, which advocate the implementation of technology and engineering measures to adapt to, rather than resist, the environmental shocks associated with intensive urban development. The research for this paper has been conducted through participatory research with local civil society groups, and aims to evaluate the role of both governmental and non-state actors in these efforts and the challenges faced in doing so. The paper concludes that research on urban resilience and urban governance must move beyond human-centered modes of thought and practice that regard cities as operating outside of ecological systems.
\end{abstract}

Keywords: urban governance, resilience, multi-species flourishing, urbanization, Malaysia, environmental imaginary 


\begin{abstract}
Introduction:
"In clearing ground, you should be cautious of not falling into a common error, in felling countries over-run with woods, which is that of causing every tree to be cut down without previously ascertaining whether they might not prove of great convenience and pleasure to the inhabitants" (John Macpherson in Gardner et al. 2011, p. 1).
\end{abstract}

In the above quote, which is an instruction from the Acting Governor General of India to Francis Light - credited as the 'founder' of George Town (Penang), Malaysia - we see how forests are a significant factor that should be considered by local governments in carrying out or authorizing development plans. The quotation alludes to how conflicting views on the use of natural resources can create considerable tension in society, and even act as a threat to the ruling political party. Penang is an island and state on the Northwestern coast of Peninsular Malaysia, with George Town as its capital and historic port and town center. Penang is now one of the most highly urbanized and most densely populated regions in Malaysia, with approximately 1.7 million inhabitants in the state, and 700,000 inhabitants on the island. The urban area is also growing at double the national average, at 3.29\% per year (Masum et al., 2017). Given a relative shortage of developable land, property speculation due to increasing land values, and a development-friendly government, new high-rise condominiums and luxury housing developments have been springing up across the island.

The central part of Penang Island is largely forested and consists of numerous steep hills, most notably Penang Hill, which is the highest and most famous peak on the island at $833 \mathrm{~m}$. The hills also contain important water catchments and forest reserves, but are nonetheless coming under increasing threat of encroaching development. This includes both legal and illegal deforestation for housing and infrastructure developments which have been combined with inadequate mitigation measures. Penang's rapid and intensive urban transition has thus put considerable pressure on the natural environment, and has had serious socio-ecological effects, such as landslides and severe 
flooding events in 2016 and 2017. Penang was thus identified as one of the deforestation hotspots in Peninsular Malaysia in 2013 (Masum et al., 2017). One problem is the lack of a gazetted Local Plan, which creates considerable ambiguity over what type of development is permissible on Penang's hillsides and allows for developers to exploit loopholes in existing policies (Mok, 2016b). Another is that $70 \%$ of forested areas in Penang are under private ownership, which makes it difficult for the government to control (Masum et al., 2017). ${ }^{1}$ This has created a strong need for new forms of urban environmental governance in Penang, which I will analyze in the latter part of this paper.

As I will discuss, the local government's response to these issues has been largely premised on the implementation of mitigation measures to allow further development. Through discursive analysis, I show how the government seems to adhere to a form of urban exceptionalism, which sees urban development as operating outside of the physical constraints of the natural environment. This mode of thought, which is common in modern resilience thinking and urban planning, attributes so called 'natural' events like flooding and landslides to climatic or geophysical events that are outside of human control (see Folke et al., 2005). Accordingly, the emphasis is placed on measures to mitigate future incidences of such hazards through natural resource management or civil engineering approaches (e.g. drainage canals and slope stabilization).

However, as various scholars have recently pointed out, this approach is quite problematic in that it ignores the ecological connectivities that are necessary for creating socially and environmentally just and desirable urban places (see Houston et al., 2017; Huber et al., 2017; Kaika, 2017). This paper thus builds on this work by reframing approaches to urban governance which tend to be largely humanistic - through the concept of multi-species flourishing. In doing so, the paper begins with a particular controversy that emerged in 2013, following the clearing of Bukit Relau, now known as Botak (Bald) Hill. This event is significant in revealing the environmental

\footnotetext{
${ }^{1}$ This situation has arisen as the Penang State Government has relied on the sale of land for much of its revenue in previous years.
} 
sensitivities of Penangites, which link the degradation of the natural environment to their social and physical well-being. Furthermore, I discuss recent participatory governance initiatives, including the Penang Hills Watch (PHW), which has sought to create broader awareness of the fragility of Penang's hillsides, and enroll more people into protecting them. This has also had political effects by putting more pressure on the State Government in monitoring and enforcing development restrictions in forested areas.

While the focus of this special issue is on the development of human flourishing, I argue that this can only be achieved by taking into account the various relationships and dependencies of humans with the broader environment and non-human actors. Following Cook and Swyngedouw's (2012) provocation to analyze how the urbanization of nature shapes socio-ecological relations, this paper revisits the concept of environmental imaginaries - originally developed in the political ecology literature - to examine how communities understand, interact and engage with the broader urban ecosystem, and how they have been incorporated into processes of urban governance. By developing a concept of environmental imaginaries as shaped by both humans and non-humans, we can begin to identify pathways to alternative forms of urban development that can enhance multispecies flourishing.

The research for this paper included key informant interviews were conducted with local residents, civil society activists, scholars, government officers, and urban planners. In addition to these interviews, I also conducted narrative analysis of local newspaper and magazine reports related to hillside developments in Penang, and personal observations of affected sites. This included walking interviews with local residents and activists in Penang's forested landscapes that have already been affected by il(legal) forest clearing, or are slated for future development projects. Following an overview of the theoretical framing, I then introduce the political-ecological transformations in Penang over the past 15 years, including the Botak Hill case, and analyze both state and non-state responses to these. Subsequently, I turn to an analysis of the environmental impacts (especially flooding) associated with hillside development in Penang. In the penultimate section, I introduce the 
Penang Hills Watch initiative and how it can be seen as a step towards multi-special urban governance. The paper concludes with some reflections on the bottom-up urban governance initiatives to inhibit the current pace of deforestation in Penang, and the importance of multi-species flourishing to fostering more socio-ecologically just urban futures.

\section{Towards multi-species flourishing: urban political ecology, resilience and environmental imaginaries}

Resilience thinking traditionally concerns the ability of a given species or ecosystem to "absorb and accommodate" environmental shocks as they arise (Holling, 1973: 21; see also Watts, 2015: 26). The concept of resilience has been influential in environmental governance for devising methods of increasing social resilience to environmental transformations. This view accepts the unpredictable character of nature, but also posits that it is socially (co)produced, through the constant managing and directing of the environment and natural processes by humans (Folke et al, 2005; GonzalezHidalgo et al. 2014; Holling, 1973). Resilience thinking has thus been criticized by political ecologists and other critical scholars who point out a number of flaws in the concept. First, it is rather anthropocentric given its focus on social wellbeing and human action (Armitage: 2008). Second, attempts which try to prevent or resist (as much as possible) environmental transformations sit uneasily with modern approaches to resilience, which often advocate techno-managerial approaches to increasing the capacity for social adaptation to the risks associated with such transformation (see Huber et al., 2017; Kaika, 2017). Gonzalez-Hidalgo et al. (2014) further argue that modern approaches to resilience thinking are fundamentally flawed due to the fact that societal responses to (or learning from) socio-ecological shocks are often curtailed by politics which prevent the formulation of alternative visions of development that are more socio-environmentally just (see also, Swyngedouw, 2010).

As such, Armitage (2008) has advocated the usefulness of political ecology approaches which stress the importance of ecological agency in shaping human-environment interactions (see also Connolly, 2016). This would involve reframing resilience by considering the wellbeing of 
entire ecosystems, rather than just humans, which would ultimately reduce the risk of disasters associated with the transformation of the environment. Accordingly, authors such as Houston et al. (2017: 2), building on the work of Anna Tsing (2015) and Donna Haraway (2016), have recently put forth the concept of 'multi-species flourishing', which seeks "an enlarged understanding of the entanglements between human and nonhuman worlds". Multi-species flourishing reflects a large body of work on more-than-human geographies, such as Jennifer Wolch's seminal 'transpecies urban theory' (1995) and subsequent concept of the 'anima urbis' (2002) which, entails a stronger moral and ethical stance towards recognizing the place of animals and other non-humans in the city, and their critical role in shaping urban life. Flora are also an important subset of non-human actors, which Houston and others have argued can be equally important to the life and spirit of urban regions. Similarly, Lorimer (2012), drawing on Bruno Latour, has put forward the idea of a 'multinatural' biogeography, which refers to the multiple trajectories along which any ecology might evolve and the various ways in which they can be sensed, valued and contested.

These concepts all help to move beyond human-centric approaches to urban-environmental governance, as encapsulated though the concept of human flourishing. Along with other scholars like Houston et al. (2017) and McCann (2002), I maintain that human flourishing is insufficient in that it does not consider the various material, spatial and biophysical aspects of the places in which urban governance takes shape. For instance, Douglass (2016: 3) states that the value of human flourishing as a central concept can be attributed to "the idea of the city as a theatre of social action and multifaceted experience of 'becoming human', including social and cultural relations”. However, this of course neglects the wellbeing of the wider biospheric environment (which Douglass terms 'planetary flourishing'). As such, in the words of Leonie Sandercock (2003), we should allow for "difference in all of its multiplicity" to flourish. While Sandercock largely referred to social and economic diversity, this understanding needs to be expanded to include environmental justice which was only hinted at in her work. 
Recognizing the importance of urban natures (in its various forms), and asking how communities understand, interact, and engage with their broader urban ecosystem can hold considerable political opportunities for the development of more sustainable and socio-ecologically just urban futures (see Braun, 2005; Francis et al., 2012; Hinchliffe and Whatmore, 2016). Or, as Kaika and Swyngedouw (2011) have put it, the multiple of existing, possible or practical socionatural relations need to be identified and explored. This in turn involves analyzing how the physical environment of particular places can facilitate (or limit) environmental movements, which has to date been poorly studied and understood. Such a move would not only make space for nonhuman actors in urban planning and governance, but also understanding human flourishing as emergent through these relations (Houston et al., 2017). One way that urban political ecologists have done this is through the concept of urban metabolism, which has been useful in understanding the processes through which nature is urbanized, and with what effects (e.g. Gabriel, 2014; Loftus, 2006; Swyngedouw, 2006).

Another useful concept is that of environmental imaginaries, which has been used by political ecologists examining social and ecological conflicts (e.g. Gabriel, 2014; Nesbitt and Weiner, 2001; Walker and Fortmann, 2003). Its value lies in the recognition of local landscapes as place-specific crystallizations made up of both discursive and material elements (see Kaika, 2006). For example, in their classical political ecological study Liberation Ecologies, Peet and Watts (1996: 263) coined the concept of the 'environmental imaginary', as “a way of imagining nature, including visions of those forms of social and individual practice which are ethically proper and morally right with regard to nature". They are rooted in particular places (and their environmental histories), and often serve as the primary source of contestations between alternative visions for those places. However, the use of this concept has been criticized for its neglect of non-human 
agency in shaping such imaginary work (see Harris, 2014; McGregor, 2004; Nesbitt and Weiner, $2001)^{2}$

As we will see in the case of Penang, the natural environment and social identity of inhabitants are closely related. Therefore, aesthetically and environmentally offensive (ab)uses of Penang's forested hillsides have strongly shaped attitudes and values regarding appropriate forms of urban development and relationships with the natural environment. For example, the Penang Hills Watch Movement and associated Penang Forum (which I will discuss in the penultimate section), formed in response to previous cases of environmental injustices in Penang and have since grown in size and influence. They have also had political effects by putting pressure on the government, and generating political opposition. For instance, a controversial proposed development project on Penang Hill in 1989/90 led to the ousting of then Chief Minister Lim Chong Eu, who had been in power for 21 years. Environmental imaginaries can thus be highly political, in that: "aesthetically offensive uses of nature can spur political opposition to the hegemonic social order" (Peet and Watts, 1996: 268).

As Maria Kaika (2017: 99) suggests, “emerging imaginaries of people and environments being and working in common" could offer more efficient and effective ways of creating more socio-environmentally just cities than traditional conceptions of resilience are able to. It is therefore important to move towards a new understanding of resilience, which goes beyond common approaches to the insertion of nature or technologies into communities to make them more tolerant to increasing levels of degradation (see Huber et al., 2017). Keil and MacDonald (2016: 1519), for example, quoting Buxton, position resilience "in terms of socio-ecological systems" and "dynamic interactions between socio-economic and biophysical systems" that operate across multiple scales. This allows us to move beyond conceptions of 'human exceptionalism', which "“blinds us' to the worlds we co-inhabit with a multitude of earthly creatures and nonhuman agents" from bacteria to animals and even pollutants (Houston et al., 2017: 5; Tsing, 2015).

\footnotetext{
${ }^{2}$ Thanks to an anonymous reviewer for highlighting this point.
} 
Yet, this also involves deconstructing the discourses put forth by urban managers, who seek to brand new capital-intensive forms of urban development as being environmentally 'efficient' or 'green'. As Houston et al. (2017: 5) point out, such modes of 'sustainable' urban design seek to "minimize impacts on the economic and social functioning of cities", and paradoxically, on the same institutional structures that undermine the development of truly sustainable and environmentally just cities. This will be the aim of the next section, which critically examines the Penang State Government's vision for a 'Clean and Green Penang', and how this has merely acted as a facade for the continued degradation of the broader urban ecosystem. I also discuss the illegal clearing of 'Botak Hill' in 2013, and its significance in re-awakening local awareness of the increasing vulnerability of Penang's natural environment.

\section{The Cultural Significance of Penang's Forested Hillsides}

It has been rightly argued that the relationship of people with the local landscape and environment in Malaysia has taken a back seat to the country's race to become a 'fully developed' nation by 2020. Accordingly, Hezri (2016) has argued that this focus on socio-economic development has resulted in many Malaysians becoming detached from the natural environment and local landscape. However, this attitude has been quite different in Penang, which has the greatest number of civil society organizations in the country, and a long history of environmental activism, making it an interesting case for this study (see Cheng and Ma, 2015). Furthermore, Penang has clearly demarcated forest reserves, and the Penang Structure Plan (PSP) disallows development on slopes steeper than a $25 \%$ gradient and/or on land higher than 75 meters. This restriction is more stringent than the federal guidelines for hillside construction, which demonstrates the strong environmental protection laws in Penang. Yet, it excludes 'special projects' which may be permitted by the State Government if they are low density developments and have strong mitigation measures in place to protect the integrity of the slopes. Due to increasing development pressure in the relatively land- 
scarce state, this exception has been frequently invoked, resulting in a marked increase in both the "extensive and intensive nature of hillside development" in Penang (Kam, 2016). ${ }^{3}$

\section{>> Figure 1 about here}

One of the most infamous (illegal) hillside developments to occur in recent years was the sudden and illegal clearing of a large swath of forested land on Bukit Relau in early 2013 to make way for a large (unpaved) road (see Figure 1). As one interviewee noted, Bukit Relau was hitherto largely taken for granted by Penangites, as it is a secondary peak on the island, and not as well known - or as accessible - as the highest peak Penang Hill (Bukit Bendera). However, the clearing was a key incident which has sparked renewed awareness about the increasing vulnerability of Penang's natural environment. For instance, the hill was quickly given the nickname Botak (bald) Hill, to reflect the very visible scar on its peak following the deforestation. Moreover, given that the land was rezoned from forest reserve into a housing development zone the year before, there was suspicion that further development would follow. Despite this speculation, the Penang State Government announced that there had been no applications for development on the Hill, and no projects planned, but that the road was built by the land owner merely to 'monitor' the site (Amarthalingam, 2013). ${ }^{4}$

Subsequently, the developer was also required to carry out 'mitigation works' to restore the hill back to its original state, and fined RM30,000 (\$6,725). Interestingly, the developer claimed at the time of the verdict that he was "willing to pay" the requisite sum to ensure the land "returns to normal”, and has reportedly invested 50 million ringgit (\$11 million) in the mitigation works to date (Amarthalingam, 2013). Nonetheless, mitigation works have now been 'underway' for nearly three years, but still have not resulted in much improvement in the hill's condition - despite Lim Guan

\footnotetext{
${ }^{3}$ For instance, given that $40 \%$ of Penang Island falls with slope gradient of higher than $25 \%$ and only $7.4 \%$ of forested land remains in Penang, the PSP has clearly been seen by the government as a mere suggestion, rather than actual law.

${ }^{4}$ However, on a personal visit to the hill, there was a man stationed at the bottom of the illegal 'road' to the summit, keeping watch over the site. The presence of this 'guard' - and his active monitoring and control of the site - raised further suspicion with my guide that the developer may be planning to develop the site further.
} 
Eng's optimistic promise that the hill would be "completely green" by the end of 2016 (quoted in Mok, 2015). On the contrary, however, the road up the hill has actually been widened, and - as I noted on a recent trip to Penang - paved. However, even if the required mitigation work were to be done, it would take a generation for the flora and fauna on top of the hill to return to its original state. This speaks to the importance of resistance to local development, rather than merely resilience which often advocates the implementation of 'mitigation' and 'restoration' techniques to carry out further development in a 'sustainable' way.

Therefore, many critics charged that the penalty to the developer was not strict enough, based on the fundamental recognition that Penangites are members of multi-species communities. For instance, the late Karpal Singh, who was a member of parliament at the time, charged that this was a significant crime to Penangites - not just the hills - and should be punished accordingly. As he put it: "hills are the heart and soul of Penangites that ought not to be touched by anyone...General Accomplishment [the developer] has assaulted and brought massive destruction on natural state assets," (Singh in Shankar, 2014). Subsequently, the ruling was amended to the maximum penalty of RM50,000 (\$11,200) in the Court of Appeal (or a one year jail term in case of default) (The Sun Daily, 2014). As the presiding judge explained: "now everyone is conscious about the environment, especially in Penang, the forests are shrinking” (Hishamudin in The Sun Daily, 2014). Through these statements, we can see how the intrinsic value of Penang's forested hillsides are central to the identity and well-being of many local people and have generated wider awareness about the need for greater environmental protection to avoid the compounding effects of such socio-natural transformations.

As such, Donna Haraway (2016: 51) has recently argued that forest well-being, in particular, "is one of the most urgent priorities for multi-species flourishing". As Penang Forum member Sharon Ahmat has put it: "these hills are fragile and easily degraded when disrupted by human activities [such as] hillside developments" (Ahmat in Dermawan, 2016). In addition to the cultural significance of the hills, they also function as important water catchments to provide water supply, 
prevent soil erosion and landslides. They further host a rich diversity of plant and animal species, and act as 'green lungs' for $\mathrm{CO} 2$ buffering, nature appreciation and outdoor recreation activities which also significantly influences the well-being of urban dwellers (Dwyer et al., 1992; Penang Forum, 2016).

In a more recent example, the Penang State Government announced plans for one of two pan-island expressways, which would connect the north coast of Penang Island to the airport in the south in 15 minutes, known as Penang Island Link 1 (or PIL1). This road is part of the controversial Penang Transport Master Plan (PTMP), and has received significant public resistance for its potential impacts on the environment of Penang, its flora and fauna, and the health and safety of its human residents (see Connolly, 2018). Figure 2 shows protesters in Penang holding up a banner which reads 'Selamatkan Bukit-Bukau Pulau Pinang' (save the hills of Penang Island). The banner pictures an anthropomorphized illustration of Penang Island with stitches on the side of its face, representing the proposed highway and a gash where $717 \mathrm{~kg}$ of dynamite would be used to construct a tunnel through the hills. The photo is thus an apt illustration of the concept of multispecies flourishing, which stresses that the wellbeing of the environment (Penang Island), flora and fauna (the monkey and birds clinging on to its sides) and humans (the girl comforting it).

\section{>> Figure 2 about here}

All of these various flora and fauna are an important part of Penang's environmental history, and have played as important a role as any human in shaping the city and its region (see Barnard, 2014: ch.1). This is not only in a biophysical sense, but also in terms of the environmental imaginaries and values of Penangites, which have been a crucial factor influencing the environmental movements and urban governance initiatives documented in the latter part of this paper. For instance, Penang's hills have been described as evoking a "special response and feeling" amongst many Penangites which is attributable to their "immense cultural and sentimental value" 
(Khor et al., 1991). The next section will discuss the severe socio-ecological impacts that incidents like the Botak Hill Development have had, before further considering how the affected communities and concerned residents are beginning to respond.

\section{Beyond Urban Exceptionalism: Ecological connectivities in Penang's urban development}

In addition to high profile cases of illegal forest clearing, there are also many examples of legal hillside development and forest clearing that are evident in many parts of Penang Island, such as the PIL1 project. The increase in approved high-rise development and indiscriminate cutting of steep hill slopes is now causing serious environmental and safety problems that are faced by various resident communities at the foothills. Between 2008 and 2015, the Penang Island Municipal Council (Majlis Bandaraya Pulau Pinang - MBPP) granted 56 approvals on land above $250 \mathrm{ft}$, many of which are high-rise, high-density projects, along with a geometric rise in illegal hill clearing cases from 2012-2015 (Kam, 2016). There is also a large area of land outside of forest reserves which is not gazetted and can be a target for illegal land clearing. As such, Penang is progressively developing at the expense of the environment, with a deforestation rate of $1.5 \%$ per annum (Masum et al., 2017).

Residents living near the hillsides - and environmentally conscious citizens of Penang - thus feel that development is getting 'uncomfortably close' (Kam, 2016). The Consumers Association of Penang (CAP) has also expressed concern over the rate that trees are being sacrificed for development. As the Botak Hill case has shown, there are laws to control this, even possible jail terms, but observers have lamented that there is often no political will to enforce them. As Jenkins (2008:23) astutely observed, there seems to be "little comprehension of the possible implications of mismanagement or the consequences of 'redefining' the planning and building laws" amongst officials in Penang. Such oversights have constituted serious barriers to the possibility of Penang for achieving a truly sustainable city on the grounds of multi-species flourishing. 
A direct consequence of the extensive hillside development and deforestation in Penang hit the island quite severely towards the end of 2016. During the Hindu festival week of Deepavali, there was a series of three flash floods that devastated large parts of the island. These were the largest floods to hit the island since the 1990s, which surprised many residents who thought that such severe flooding was a thing of the past. ${ }^{5}$ However, the Penang State Government was quick to rebut claims that extensive development was the cause of the floods (Puah, 2016a; 2016b). For instance, the state's Drainage and Irrigation Department (DID) concluded that the flash floods in George Town were due to "unsystematic drainage system and continues heavy rain" [sic] (The Rakyat Post, 2016). This was dismissed by Universiti Sains Malaysia (USM - University of Science) Professor Chan Ngai Weng, who pointed out that "it is unwise to dismiss rapid development and hillslope cutting as the cause of the flash floods" (Phuah, 2016). Indeed, most of Penang's current hotspots for flooding are concentrated in the northeastern part of the island, which is also the most built up area. Thus, as two Penang residents wrote in a letter to the Malaysiakini newspaper: "the flash floods and the landslide in Penang are proof that we have drastically underestimated the impact of manmade changes to the island and its ecology, and its ability to mitigate natural disasters" (Rawther \& Rawther, 2017).

As a result of such events, Masum et al. (2017) have recommended an immediate ban on hill-land development to ensure overall environmental safety in Penang. Yet, in attempting to mitigate against future flooding, the Government has not announced any plans to slow down development on the island - even in forested hillside areas - but has simply stated that it will focus on upgrading drainage systems in every neighbourhood (The Rakyat Post, 2016). In other words - the solution is more development. For instance, a recent news article reported that the State Government is planning to begin ten flood mitigation projects in mid-2017 worth a total of RM300 million (\$67 million), opening the projects up for tender to developers (Mok, 2016a). However, it is clear that

\footnotetext{
${ }^{5}$ At the time of revising this paper, there was an additional case of severe flooding and landslides that took place at the start of the rainy season in September, 2017.
} 
Penang needs to move beyond such urban planning approaches that are based on human exceptionalism, and towards building a more reciprocal relationship with the natural environment, which would largely alleviate the need for such mitigation measures. This would involve, for example, limiting hillside developments which could result in a degradation of the natural environment, as advised by the Penang Structure Plan. Unfortunately, as Rawther \& Rawther (2017: np) lamented, Penang's politicians "seem to forget that we cannot survive on Earth without a balanced ecosystem".

As mentioned above, flooding is nothing new to Penang. As early as the mid 1990s, Penang Island was plagued by constant flooding and environmental damage caused by irresponsible developers, with new suburban townships springing up from former agricultural or forested areas "almost overnight" (see Jenkins, 2008: x).Thus, after the recent flooding episode, one resident, Mohamad, complained, "I am tired of hearing repeated excuses from the state government, attributing the flash floods to the so-called 'King' Tide and tidal change pattern. Nothing has been done to mitigate the flash floods for far too long, I am saddened that the analysis and much-politicised flood mitigation schemes have come to nothing" (quoted in Phuong, 2016). Civil society members have also raised concern about the downstream impacts of upstream development and the inequity between public and private costs stemming from these projects.

Such concerns raise classical questions in political ecology, such as development for whom? Who are the beneficiaries and who pays the social and environmental costs of such development. They also raises the need to move beyond urban exceptionalism frames which view human societies as being able to operate outside of ecological consequences. For instance, while development in Penang - either for housing or infrastructure (road) construction - is often framed as beneficial for all Penangites (through job creation and economic growth), the sustainability and desirability of such development is often forgotten. This refers not only to potential impacts like floods and landslides (which also incur significant social and economic costs), but also the loss of flora \& fauna, which have been shown to be vital to quality of life, well-being and overall social \& 
environmental health. In the next and penultimate section, I will consider a participatory governance initiative known as Penang Hills Watch that has been launched by local civil society actors to cultivate a stronger civic culture centered on raising awareness of the harms associated with unscrupulous hillside developments.

\section{The Penang Hills Watch and potential pathways to multi-species flourishing}

In October, 2016, a citizen's initiative called Penang Hills Watch was launched which is designed to monitor incidences of hill clearing in Penang, and galvanize support for safeguarding what is left of the State's forests. The Penang Forum is a 'loose coalition' of NGOs (non-governmental organizations) in Penang, which aims to "promote participatory local democracy, sustainable planning and development, economic justice, affordable housing, environmental consciousness, sustainable transport, workers' rights and heritage conservation" (Penang Forum, 2012). It was formed between 2007 and 2008 through civic responses to previous development initiatives in Penang, notably the anti-Penang Global City Centre Project of 2008, which was a proposed megaproject to be located on the grounds of the Penang Turf Club, near George Town. The Penang Forum has a steering committee which plans events and campaigns, but is not dominated by one individual or group. The group gets its name from the regular public forums which are held to get input from concerned residents on local development and conservation issues. Many of the members communicate informally through various WhatsApp groups, including the 'Penang Hills Watch' group, which shares information on hill clearings in Penang and the associated socioecological impacts.

PHW allows local residents to report cases of suspected illegal hill clearing from their mobile phones, which are then posted to an interactive map (including photos and details of each case) allowing for the identification of patterns of hillside development in Penang (https://hillclearinginpenang.ushahidi.io/views/map). The data is then collated by members of the Penang Forum and forwarded to the State Government to help provide a comprehensive picture to 
the authorities of the number of hill clearing events taking place and their effects. The platform thus provides quantifiable evidence of the increasing degradation of the local environment in Penang and creates awareness of this amongst both the government and the wider public. This is one of the key merits of the project, in that it allows for the various relationships and dependencies of Penangites with their broader environment to be recognized, explored and acted upon. ${ }^{6}$

The initiative also involves the active participation of the State Government, who are requested to respond to quarterly reports from Penang Hills Watch to provide clarification on the nature of the activity, including: 1) the development's legality; 2) its purpose 3) the site's land use status; 4) action to be taken by the City Council or State Government. Upon submission of the first quarterly report, there 126 cases of hillside clearing, including 86 from government records, and 40 from the public. Of these, approximately 89 were illegal clearings, 26 were approved developments, six were under investigation and one was a natural slope failure (Penang Forum, 2017). ${ }^{7}$ The PHW project is consistent with one of the central tactics of NGOs in Malaysia, which involves the provision of expertise and development of in/formal contacts with government officials in order to develop a more effective and trust-based working relationship (see Hezri, 2016; Cheng and Ma, 2015). It is also an important urban governance initiative because the State Government and City Council largely lack the resources (and political will) to do such monitoring itself - but also provides transparency to the public regarding the protection of Penang's natural environment. As Masum et al. (2017) have suggested, such co-management and enforcement of environmental laws can help to ensure a more sustainable future for Penang.

The Penang Hills Watch can thus be seen as a key type of initiative that can help to cultivate a multi-species sensibility more widely amongst members of a community. For instance, it encourages similar modes and practices as the concept of multi-species flourishing does, including

\footnotetext{
${ }^{6}$ One limitation, however, is that it requires a smart phone (with GPS) to take photos and record information about the clearing, which may exclude some members of the population.

${ }^{7}$ Remaining cases were duplicates of the same site.
} 
interacting with, observing, and being involved in the wellbeing of nonhumans through activities such as hikes or simply looking through one's window. It is also a bottom-up approach, which came about through increasing public concern over the increasing encroachment of human activities on Penang's hillsides, reducing the extent and integrity of remaining natural habitat. Through galvanizing wider awareness and stewardship of the natural environment, the Penang Hills Watch movement - and others like it - can act as key stimulus to safeguard and nurture the type of multispecies flourishing that is central to sustaining urban ecosystems and quality of life.

Some critics have argued that, because the PHW is focused on information sharing, the initiative may not actually have that much impact due to the the numerous 'special cases' of approved works on forested or hillside sites, mentioned above. These demonstrate that the government is already aware of and has approved many of the hill clearing projects, thus inviting speculation that the developers and local authorities are somehow complicit in these events. Moreover, as the 'Botak Hill' case clearly shows, the enforcement action taken by the government often has no teeth, as mitigation and restoration works are never fully enforced. The stop work orders issued to illegal developers often achieve just that - they stop work, leaving bald patches of exposed hillside which are subject to further erosion and landslides. However, the collaborative approach with the government can also serve to remind officials of the importance of protecting the hillsides. Furthermore, given that a goal of the PHW is also to enhance public awareness about hill clearing issues and impacts, it could act as a catalyst for putting pressure on Penang's politicians to begin taking the integrity of the environment seriously.

Finally, a major collaborative effort has been underway since 2016 to secure a UNESCO Biosphere Reserve listing for Penang Hill, which would create additional protected space for flora and fauna in Penang, and facilitate inter-special interaction. Biosphere Reserves are research-driven conservation programs that promote solutions for reconciling the conservation of biodiversity with the sustainable use of a site (UNESCO, 2017). They are nominated by national governments, and the Penang Hill movement is being led by a group of actors including Penang Hill Corporation 
(PHC) and State Forestry Department (government bodies in charge of monitoring and maintaining the Hill); The Habitat (a private sector eco-tourism venture) and the local University of Science, Malaysia (USM). The rationale for the nomination is the rich biodiversity of the hill, which contains several endemic species of orchids, ants and spiders as well as over 100 species (about $80 \%$ ) of the island's birds found on the hill (The Star, 2016). Having Penang Hill listed as a biosphere would allow for greater protection of the hill, as well as promoting more people to interact with and understand the significance of the hill and its flora and fauna. Along with PHW, this would be a positive step towards achieving a form of urban governance on the grounds of multi-species flourishing which would help to alleviate some of the pressures currently threatening the long-term viability of Penang and its urban ecosystem.

\section{Conclusion}

This paper has outlined the increasing development pressures on the forested hill-land on the island-state of Penang, Malaysia, and has detailed the significant environmental and socio-cultural implications associated with this activity. In tracing local responses to these developments, the paper has analyzed how the importance of socio-ecological connectivities have been mobilized by local actors in developing a more sustainable future for Penang. The paper has thus argued for a widening of the concept of urban governance along the lines of multi-species flourishing, and to move beyond resilience approaches which only constrain possibilities for socio-environmental justice. As I have demonstrated with examples from the Penang experience, such approaches see urban development as separate from ecological systems, and thus often rely on the implementation of technology and civil engineering measures to mitigate against future environmental shocks. On the contrary, the paper has shown how urban development and environmental harms such as landslides and flooding events are actually closely connected, thus requiring a fundamentally different approach to urban planning. 
In his book Concrete and Clay, Matthew Gandy (2002:11) has argued that "if we want to incorporate the independent agency of nature into our analysis, we need to be sensitive to the way in which biophysical processes are mediated through human cultures". This paper has attempted to do just that, through illustrating the environmental imaginaries of Penangites, and their reactions to events such as the Botak Hill clearing, which are largely based on experiences in and with the natural environment. The Botak Hill case has sought to demonstrate how such aesthetically and environmentally offensive (ab)uses of nature have created greater recognition of the fragility of Penang's ecosystems, and the need for new structures of urban governance. This has been encapsulated in the Penang Hills Watch initiative, which has sought to mobilize even more people into generating collective response to the harms of capital intensive development. Such social movements are vital to fashioning a model of urban development that is socially and ecologically sustainable in the context of intensifying transformations of nature associated with Asia's urban transition.

In order to do so, I have suggested that we must give analytical priority to the various existing and potential socio-ecological relationships in a particular place, and how they might be reworked in a more equitable manner. As I have argued, this can help to reimagine a different form of 'resilient' and 'sustainable' cities, which are not simply based on 'adding' nature or technological measures to offset further development and socio-ecological injustices. This explains the importance of the concept of multi-species flourishing, which can re-frame the question of urban resilience in terms of the myriad socio-ecological dependencies on the wider geophysical environment and non-human species in a particular place. Without such a shift in approach, rapidly urbanizing cities like Penang will continue to be impacted in compounding ways by the unregulated interventions into nature that are currently increasing in both frequency and severity.

\section{Acknowledgements:}


The research for this paper was made possible by a research grant provided by the Asia Research Institute, National University of Singapore. Earlier drafts of the paper received valuable comments from Michelle Miller and three Urban Studies reviewers, which helped to clarify my writing and strengthen the arguments. Thanks also to Rexy Chacko for time and insights given during the research for this paper, and sharing his photograph used here (Figure 1).

\section{References:}

Amarthalingam S (2013) 'There will be no development on Bukit Relau': Tycoon. Anilnetto.com. Available at: http://anilnetto.com/economy/development-issues/there-will-be-nodevelopment-on-bukit-relau-tycoon/ (accessed 9 February 2017).

Armitage D (2008) Governance and the commons in a multi-level world. International Journal of the Commons 2(1): 7-32.

Barnard TP (2014) Nature contained: environmental histories of Singapore. Singapore: NUS Press. Available at: http://muse.jhu.edu/books/9789971698072/ (accessed 22 September 2016).

Braun B (2005) Environmental Issues: Writing a 'more than human' urban geography. Progress in Human Geography (29): 635-650.

Cheng EW and Ma S (2015) A City's Status and its civil society. Penang Monthly, 14 January. Available at: http://penangmonthly.com/article.aspx?pageid=2665\&name=a_citys_statu_s_and_its_civil_ society (accessed 29 March 2017).

Connolly C (2016) ‘A Place for Everything': Moral landscapes of 'swiftlet farming' in George Town, Malaysia. Geoforum 77: 182-191. DOI: 10.1016/j.geoforum.2016.11.005.

Connolly C (2018) Worlding Cities Through Transportation Infrastructure. Environment and Planning A: Economy and Space https://doi.org/10.1177/0308518X18801020. 
Cook I and Swyngedouw E (2012) Cities, social cohesion and the environment: towards a future research agenda. Urban Studies 49(9): 1938-1958.

Dermawan A (2016) Group launches Penang Hills Watch site to monitor hill clearing activities. Available at: http://www.nst.com.my/node/184600 (accessed 8 December 2016).

Douglass M (2016) Creative communities and the cultural economy — Insadong, chaebol urbanism and the local state in Seoul. Cities 56: 148-155. DOI: 10.1016/j.cities.2015.09.007.

Dwyer JF, McPherson G, Schroeder HW, et al. (1992) Assessing the Benefits and Costs of the Urban Forest. Journal of Aboriculture 18(5): 227-235.

Folke C, Hahn T, Olsson P, et al. (2005) Adaptive governance of social-ecological systems. Annual Review of Environment and Resources 30(1): 441-473. DOI: 10.1146/annurev.energy.30.050504.144511.

Francis RA, Lorimer J and Raco M (2012) Urban ecosystems as 'natural' homes for biogeographical boundary crossings. Transactions of the Institute of British Geographers.

Gabriel N (2014) Urban Political Ecology: Environmental Imaginary, Governance, and the NonHuman. Geography Compass 8(1): 38-48.

Gandy M (2002) Concrete and Clay: Reworking Nature in New York City. London: MIT Press.

Gardner S, Sitthisunthộn P and Lai EM (2011) Heritage trees of Penang. Penang, Malaysia: Areca Books.

González-Hidalgo M, Otero I and Kallis G (2014) Seeing beyond the Smoke: The Political Ecology of Fire in Horta de Sant Joan (Catalonia). Environment and Planning A 46(5): 1014-1031. DOI: $10.1068 / \mathrm{a} 45600$. 
Haraway DJ (2016) Staying with the trouble: making kin in the Chthulucene. Experimental futures: technological lives, scientific arts, anthropological voices. Durham: Duke University Press.

Harris LM (2014) Imaginative Geographies of Green: Difference, Postcoloniality, and Affect in Environmental Narratives in Contemporary Turkey. Annals of the Association of American Geographers 104(4): 801-815. DOI: 10.1080/00045608.2014.892356.

Hezri A (2016) The sustainability shift: refashioning Malaysia’s future.

Hinchliffe S and Whatmore S (2006) Living Cities: Towards a Politics of Conviviality. Science as Culture 15(2): 123-138.

Holling CS (1973) Resilience and Stability of Ecological Systems. Annual Review of Ecology and Systematics 4(1): 1-23. DOI: 10.1146/annurev.es.04.110173.000245.

Houston D, Hillier J, MacCallum D, et al. (2017) Make kin, not cities! Multispecies entanglements and 'becoming-world' in planning theory. Planning Theory: 147309521668804. DOI: $10.1177 / 1473095216688042$.

Huber A, Gorostiza S, Kotsila P, et al. (2017) Beyond “Socially Constructed” Disasters: Repoliticizing the Debate on Large Dams through a Political Ecology of Risk. Capitalism Nature Socialism 28(3): 48-68.

Jenkins G (2008) Contested Space: Cultural Heritage and Identity Reconstructions Conservation Strategies within a Developing Asian City. Zurich: Lit Verlag.

Kam SP (2016) 'The Natural Heritage and Environmental Costs of Penang's Development'. Seminar. Singapore. Available at: https://ari.nus.edu.sg/Event/Detail/e750e257-e3c6-4309a54d-0407786fcbe8. 
Kaika M (2006) Dams as Symbols of Modernization: The Urbanization of Nature between Geographical Imagination and Materiality. Annals of the Association of American Geographers 96(2): 276-301.

Kaika M (2017) ‘Don’t call me resilient again!' : the New Urban Agenda as immunology ... or ... what happens when communities refuse to be vaccinated with 'smart cities' and indicators. Environment and Urbanization 29(1): 89-102.

Keil R and Macdonald S (2016) Rethinking urban political ecology from the outside in: greenbelts and boundaries in the post-suburban city. Local Environment 21(12): 1516-1533.

Khor M and Friends of Penang Hill (eds) (1991) Penang Hill: the need to save our natural heritage: critique of the proposed development and alternative plan. Penang, Malaysia: Friends of Penang Hill.

Loftus A (2006) The Metabolic Processes of Capital accumulation in Durban's Waterscape. In: Heynen N, Kaika M, and Swyngedouw E (eds), In the Nature of Cities: Urban Political Ecology and the Politics of Urban Metabolism, Questioning Cities Series, Abington and New York: Routledge, pp. 173-190.

Lorimer J (2012) Multinatural geographies for the Anthropocene. Progress in Human Geography 36(5): 593-612.

Masum KM, Mansor A, Sah SAM, et al. (2017) Effect of differential forest management on landuse change (LUC) in a tropical hill forest of Malaysia. Journal of Environmental Management 200: 468-474. DOI: 10.1016/j.jenvman.2017.06.009.

McCann E (2002) Space, citizenship, and the right to the city: A brief overview. GeoJournal 58(2/3): 77-79. 
McGregor A (2004) Sustainable development and 'warm fuzzy feelings': discourse and nature within Australian environmental imaginaries. Geoforum 35(2): 593-606.

Mok O (2015) Penang's 'Botak Hill' will be green by end of next year, says Guan Eng. Malay Mail Online. Available at: http://www.themalaymailonline.com/malaysia/article/penangs-botakhill-will-be-green-by-end-of-next-year-says-guan-eng (accessed 9 February 2017).

Mok O (2016a) Penang’s RM300m flood mitigation projects to start 2017. Available at: http://www.themalaymailonline.com/malaysia/article/penangs-rm300m-flood-mitigationprojects-to-start-2017 (accessed 29 September 2017).

Mok O (2016) Penang planning committee the final arbiter in planning conflicts. Available at: http://www.themalaymailonline.com/malaysia/article/penang-planning-committee-the-finalarbiter-in-planning-conflicts (accessed 9 December 2016).

Nesbitt JT and Weiner D (2001) Conflicting environmental imaginaries and the politics of nature in Central Appalachia. Geoforum 32(3): 333-349. DOI: 10.1016/S0016-7185(00)00047-6.

Peet R and Watts M (eds) (2004) Liberation ecologies: environment, development, social movements. 2nd ed. London: Routledge.

Penang Forum (2012) About Us. Available at: https://penangforum.net/about/ (accessed 12 March 2018).

Penang Forum (2016) Penang Forum launches Penang Hills Watch online crowd-sourcing, mapping initiative. Penang Forum, Blog. Available from: https://penangforum.net/2016/10/31/penang-forum-launches-penang-hills-watch-onlinecrowd-sourcing-mapping-initiative/ (accessed 14 February 2017). 
Penang Forum (2017) Penang Forum discusses its Penang Hills Watch Report 2016 with state government. Available at: https://penangforum.net/2017/02/04/penang-forum-discusses-itspenang-hills-watch-report-2016-with-state-government/ (accessed 14 February 2017).

Phuah KL (2016) 'Rapid development, hillslope cutting irrefutably cause of Penang floods' | New Straits Times | Malaysia General Business Sports and Lifestyle News. Available at: http://www.nst.com.my/news/2016/11/186258/rapid-development-hillslope-cuttingirrefutably-cause-penang-floods (accessed 7 December 2016).

Sandercock L (2003) Cosmopolis II: mongrel cities in the 21st century. London ; New York: Continuum.

Shankar A (2014) One month ultimatum to repair 'Botak Hill' | Free Malaysia Today. Available at: http://www.freemalaysiatoday.com/category/nation/2014/01/06/one-month-ultimatum-torepair-botak-hill/ (accessed 9 February 2017).

The Rakyat Post (2016) Penangites fume at evening flash floods.

The Star (2016) Biosphere Reserve pitch for Penang Hill. 6 October. George Town, Malaysia. Available at: https://www.thestar.com.my/news/nation/2016/10/06/biosphere-reserve-pitchfor-penang-hill/.

The Sun Daily (2014) Developer fined RM50,000 for illegal hill-clearing activities. Available at: http://www.thesundaily.my/news/1101575 (accessed 9 February 2017).

Swyngedouw E (2006) Circulations and metabolisms: (Hybrid) Natures and (Cyborg) Cities. Science as Culture 15(2): 105-121.

Swyngedouw E (2010) Apocalypse Forever? Theory, Culture \& Society 27(2-3): 213-232. DOI: $10.1177 / 0263276409358728$. 
Tsing AL (2015) The mushroom at the end of the world: on the possibility of life in capitalist ruins. Princeton: Princeton University Press.

UNESCO (United Nations Educational Scientific and Cultural Organization) (2017) Biosphere Reserves - Learning Sites for Sustainable Development. Available at: http://www.unesco.org/new/en/natural-sciences/environment/ecological-sciences/biospherereserves/.

Walker P and Fortmann L (2003) Whose Landscape? A political ecology of the 'exurban' Sierra. Cultural Geographies 10: 469-491.

Watts M (2015) Now and then: the origins of political ecology and the rebirth of adaptation as a form of thought. In: Perreault TA, Bridge G, and McCarthy J (eds) The Routledge handbook of political ecology. Routledge international handbooks. London ; New York, NY: Routledge, Taylor \& Francis Group, pp. 19-50.

Wolch J (2002) Anima Urbis. Progress in Human Geography 26: 721-42. 


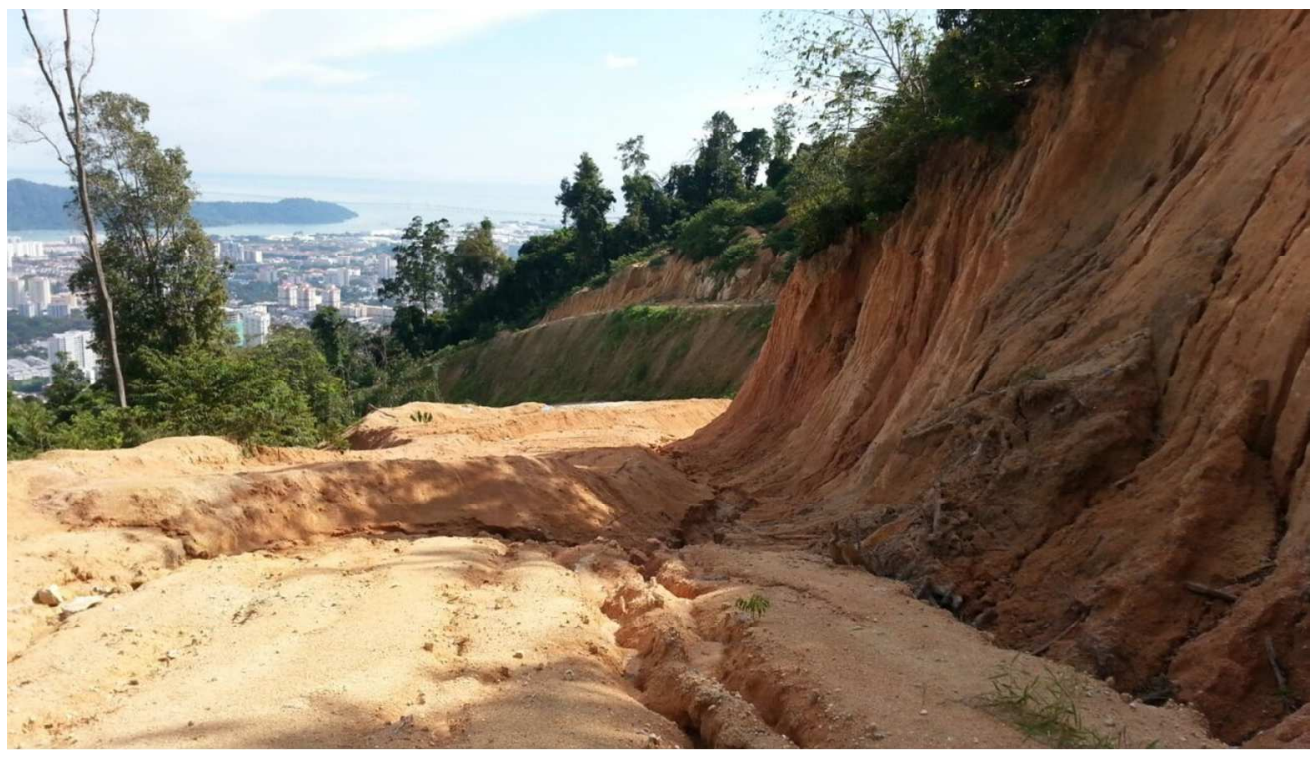

Figure 1: Summit of 'Botak Hill', which used to be primary forest until the illegal clearing in 2013 Photo by Rexy Chacko, January 2017.

$535 \times 304 \mathrm{~mm}(72 \times 72$ DPI $)$ 


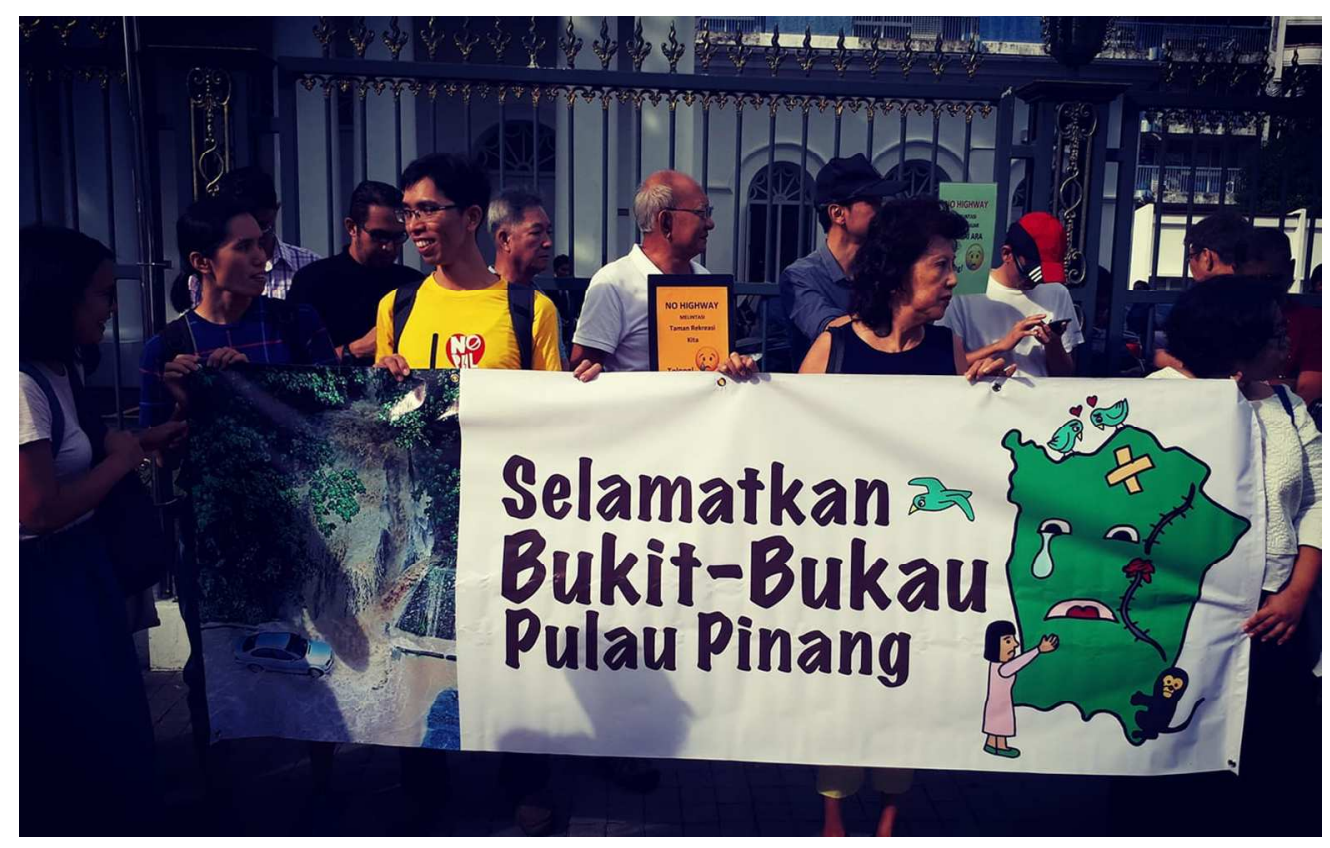

Figure 2: a protest against the Penang Island Link Highway 1 (PIL1) in Penang on August 9th, 2018. Source: www.facebook.com/StopPIL1/

$508 \times 320 \mathrm{~mm}(72 \times 72$ DPI $)$ 